\title{
Heidegger in Conversation With Heidegger
}

The organisers,

Emanuele Mariani

Irene Borges-Duarte

\section{(c) (7) (8) 5 sciendo}

Entirely dedicated to Heideggerian thought, the present issue of Phainomenon brings to maturity the fruits of what, at the beginning, was a meeting between scholars, recognized or in the early stages of their careers, linked by institutional affiliation or elective affinity to the Portuguese language and culture. That meeting took place in Évora in 2019, on the basis of a partnership between the University of Évora and the University of Lisbon, under the title of "II Jornadas Heideggerianas", and it intended to carry on the investigations started in the first "Jornadas Heideggerianas de Évora," an event organised in 2013 with the aim of establishing a dialogue between those who, in Portugal, dedicate themselves totally or partially to the study of Martin Heidegger's thought and to the translation of Heidegger's work into Portuguese. More than the title, however, it is the subtitle of the 2019 meeting that allows us to understand the leitmotiv that unites all the contributions presented here: "Heidegger in conversation with Heidegger".

Heidegger's self-interpretation of his own trajectory offers, in fact, an essential working criterion for the historical-conceptual analysis of the constituent moments of Heidegger's philosophical vision. The great complexity of such vision raises, at a hermeneutical level and in a very specific sense, the problem of the unity of the work - the Heideggerian work, conceived as a 
"path," in Heidegger's own, explicit words, i.e., built step by step, through tracks, detours and jumps. No less essential, on the other hand, is the questioning to which Heidegger has constantly subjected, at a theoretical level, the results or, better, the stages reached along his own trajectory. This questioning coincides, in essence, with the gesture of a meditative and problematising reflection, that is, a philosophical reflection, with a kind of inner dialogue aimed at capturing the motivations, the hesitations and, no less importantly, the unexplored possibilities of the "thing itself", to put it in Heideggerian terms, that thought is called upon to think.

In this regard it is worth quoting the words addressed to Elisabeth Blochmann in a letter dated 18 November 1932, in which Heidegger does not hesitate to affirm the requirement for reflection that impose s itself before any external confrontation with other figures of philosophy. This requirement appears with even greater force if we consider that, at that time, the academic community was still waiting - in vain - for the second part of Being and Time to be published and that, since 1931, both Husserl and Cassirer had openly expressed their criticisms of the first part of that work:

For the moment I am reading my manuscripts, I mean, reading myself. And I must say that, both positively and negatively, I find it much more fruitful than other readings, which I neither want to do nor have the occasion to do. (Briefwechsel, 53)

Today, confirming what has become evident since 1989, with the publication of the Beiträge (GA 65), Heidegger's topological attention to the progression of his own research assumes, if possible, even greater importance by virtue of the most recent publications of the Gesamtausgabe. One need only think of volumes 73 (1 and 2), 76 and, above all, 82, and also of much of the content of the Black Notebooks, though in the latter case the interpretation has suffered, at least so far, from a certain one-sidedness. The contributions collected here follow, each in its own way, this hermeneutic line, by choosing as research themes topical aspects of Heideggerian thought such as "affectivity", "otherness", "spatiality", "dispositions", etc., in an attempt to shed light, directly or indirectly, on the general meaning of Heidegger's work 
through the filter of two paradigmatic and related guiding images: the "conversation" and the "path".

These are autonomous contributions that partly dialogue with each other, and that we may summarize in the following terms through a quick synoptic look. Irene Borges-Duarte, with The Path and the Conversation, defines and confirms the theme of the collection, by retracing the main stages of Heidegger's work according to Heidegger's own self-interpretation. Between temporality conceived as the transcendental horizon through which Heidegger, in 1927, formulates the Seinsfrage and the Ereignis that, from the 1930s onwards, opens up the possibility of another articulation of the dynamic relationship between being and time, the focus is particularly on the transition that Heidegger makes at the end of the 1920s through the confrontation with Kant, in which we witness the elaboration of a metaphysics of Dasein that will serve as a "bridge" to the "new path" with which the pages of the Beiträge are measured.

Bernard Sylla, with Existential Spatiality in Being and Time, by drawing on a critique of Sloterdijk to Heidegger, reconstructs Heidegger's revisions of the very conception of space in Being and Time. The aim is to highlight a dimension of spatiality that could be glimpsed in existential analysis, but which had not been fully explored in its systematic consequences: a spatiality intersubjectively reconfigured as a function of Mitdasein, from which new possible articulations of "space", existentially understood, would result. The originality of this proposal is accompanied by an analysis of the revision to which Heidegger, in dialogue with himself, subjects the primacy of temporality over spatiality by virtue of the Ereignis as the common origin of both.

Chiara Pasqualin's article, Is a "Pathic" Pre-Predicative Experience Conceivable? presents an original analysis of the concept of ante-predicative, carrying out an alternative interpretation of the results of a secondary literature that frequently, and perhaps too quickly, identifies the "ante-predicative" with the "pre-theoretical". According to Pasqualin, the pathic ante-predicative should be interpreted as preliminary to the hermeneutic articulation of the Inder-Welt-sein, being in direct relation with the Befindlichkeit as the original opening of Dasein that is in turn previous, if not in a genetic sense, at least in 
an ontological one, to the Verstehen. From here arises the possibility of affirming the primacy of the empathic dimension as pre-signifying and, consequently, pre-hermeneutic, whose systematic effects make an impact on the figure of the "great silence" that Heidegger faces in the 1930s.

Starting from $\S 42$ of Being and Time in which Heidegger, as we know, evokes Hyginus' fable about the origin of man from humus by the work of Care, Luís Gabriel Provinciatto's article, The (Con)Text of a Note: Heidegger and the Factical and Pre-Ontological Aspects of Care, aims to analyse the different conceptual frameworks that we find at the basis of the formulation of the phenomenon of Sorge, and that Heidegger makes explicit in a footnote: Augustinian anthropology and Aristotelian ontology. The inflection dictated by existential analysis would thus make it possible to appreciate the factual and, at the same time, ontological character of care as the fundamental and unitary structure of the being of Dasein, highlighting its transcendental dimension.

Focusing on the concept of disposition, Helder Telo in Passivity and Activity in the Heideggerian Description of Dispositions pursues a textual examination of some of the most significant places in the Heideggerian work where it is possible to perceive the originality of a specific understanding of the emotional-affective dimension of man. This understanding would be capable of challenging the dichotomy between passivity and activity that emerges from the most recent proposals in the current debate, while complementing the basically aporetic results to which the legacy of the history of philosophy leads. Object of description and methodological concept of the existential analysis, the theme of "dispositions" would lose, between the 1920s and 1930s, the transcendental function that Heidegger initially attributed to it. In this, Telo takes the opportunity to multiply the models for understanding the concept of "disposition", proposing, from a hermeneutic point of view, an additional parameter to measure the internal progression of the Heideggerian path.

Starting from $\S 29$ of Being and Time and focusing on the concept of Befindlichkeit, Maria Adele Pacheco proposes in Otherness and Affectivity in Dialogue with Being and Time a broad and articulated reading that, crossing, albeit quickly, almost the entirety of Heideggerian thought, aims to attest the presence in Heidegger of a thought of otherness. Beyond Being and Time, the analysis focuses on the Beiträge of the 1930s, on the reading of Hölderlin and of Greek tragedy, so as to eventually dwell on the problem of technique and on 
the ontological quadrature of the Geviert. The relation between Befindlichkeit, Stimmungen and solipsism serves in this sense as a thread to illustrate how, with reference to the problem of otherness, the absence of an ethics explicitly formulated by Heidegger in no way signifies its impossibility.

In Heidegger and the Overcoming of his Transcendental Understanding of the World, Dominique Mortiaux presents a global reading which, starting from Being and Time, finds a possible realisation of Being and Time's intrinsic incompleteness in the question of technique and in the overcoming of nihilism. From the understanding of being based on the transcendental understanding of the world, the core of the analysis shifts to the understanding of being as history. The focus is ultimately on the connection between speaking and listening in the light of the dialogue with poetry, which serves as a key to accessing the thought of being.

In conclusion, we would like to say a word about the choice of keeping the Portuguese language for the publication of this issue: obviously, that choice was not dictated by reasons of cultural identity having to do with an alleged specificity of Heideggerian studies in Portugal; neither should it be understood as the result of a contingency. If dialogue, whether understood Platonically or in Heideggerian terms, is an essential moment of doing philosophy, philosophy as symphilosophein can in no way be abstracted from the sense of a community, real or virtual, made of ideas or people, under penalty of its devitalization. We therefore wished, as far as possible, to preserve the living character of the encounter which language belongs to, and which allowed us to "walk together", even if only for a short distance, making the journey an opportunity to talk to oneself and to each other. We thus like to think, as fellow travellers, that it is the way that seeks the travellers. 